the inertia or mass of the electron could be completely attributed to the reaction of its electric field, if the charge was supposed as concentrated in a sphere of radius $10^{-13} \mathrm{~cm}$. According to this, the law of motion of an electron turns out to be equivalent to the statement that the electron moves so that the total force on it, as determined, by the resultant field, is zero. This 'Lorentz principle' is equivalent to the conservation of energy, momentum and moment of momentum for any system of electrons if we associate these magnitudes not with the electrons themselves but with the electromagnetic fields they produce.

That the concepts of conservation of energy, momentum, and moment of momentum, which arose in the mechanics of moving particles, could be applied to the electromagnetic field, had been realized before Lorentz put forward his theory. It was, however, only after the inertia of the electron had been explained as the result of electromagnetic reaction that its kinetic and potential energy could be treated as the electric and magnetic energy of its field.

In this way the electromagnetic field was shown to be the vehicle of all the mechanical properties (energy, mass, momentum, ete.) which were earlier ascribed to miterial particles. The particles were thus considered not as sources of fields but as products of them-rather like knots in the lines of force. The question of the force of interaction between these 'knots', like the question of selfreaction, loses its meaning, as the resultant force experienced by each of them is zero. The laws of motion of the particles formed by the field agree completely with the law of conservation of energy and momentum of the field.

The further development of field theory concerns the solution of three types of problems: first, problems of the structure of electrons and the atomic nature of electric charge; secondly, the dynamics of nuclear fields; and thirdly, the quantization of dynamical fields.

The structure of the electron has been tackled hitherto from two angles, one treating it as a point charge and the other as if it had extension. Along both avenues of approach insuperable difficulties have been encountered. These difficulties, as also those connected with the atomic nature of the charge, will probably be solved by a thorough application of quantum theory ideas, but before this is possible we need further development of modern quantum mechanics.

The importance of the dynamics of nuclear fields is due to our ascribing the inertia of nuclear particles to the reaction of their own fields. The attempts which were made earlier to treat the inertia of protons as due to the reaction of their electromagnetic field lost their meaning when the neutron was discovered, for the neutron, even without electric charge, has a mass very close to that of the proton. In a number of papers to-day this non-electromagnetic mass is treated as a magnitude corresponding to some nuclear 'charge' bearing the same relation to the nuclear fields as the electric charge does to the electromagnetic field. The protons and neutrons themselves are thus regarded as 'knots' in a nuclear field, either apart from or in combination with an electromagnetic field.

From this point of view matter is a collection of interpenetrating dynamical fields, electromagnetic and nuclear, with material particles and bodies forming knot points. These points can under certain conditions appear and disappear, although the energy of the field, the momentum and other fundamental properties remain unchanged.

- This picture is still only a provisional sketch. In order to complete it we need further development of the ideas of the quantum theory. The essence of this theory is an organic statistical synthesis of continuity and discontinuity. It was first introduced in the studies of the motion of particles and of light, and through the development of the quantum aspect of dynamical fields has helped enormously towards the solution of the problem of matter. As a result, new particles have appeared on the physics scene. These are in addition to those which create, or are created by, the known dynamic fields, and serve as vehicles of interaction between the original particles.

In the case of electromagnetic fields, for example, the sources, or if you like products, of which are electrons, the corresponding quantum particle, the transmitter of electromagnetic action is the photon. In the case of nuclear fields ereated by protons and neutrons, the corresponding quantum particle is apparently the meson. On the other hand, mesons, like electrons, take part in the creation of the electromagnetic field. This prompts the very natural thought that in a sense all particles are quanta with respect to some other particles. In particular, the electron positron pair could in all probability be treated as quanta of some as yet unknown field, which in its turn is created by other particles, for example, the nueleons. But the nucleons could play the same part in relation to other particles probably as yet undiscovered.

But here we are crossing the boundaries of modern physical science and risk falling into the realm of unscientific phantasy. Nevertheless, recent developments of physics have shown how limited and narrow our previous ideas about the physical world were, so in a survey of the problems of modern physics we need not fear a certain extension of its frontiers, even if it is not yet fully justified.

\section{VALUE TO THE STUDY OF CHINESE CIVILIZATION OF COLLECTIONS AND MUSEUMS IN BRITAIN}

\author{
By Prof. W. PERCEVAL YeTtS, C.B.E. \\ Professor of Chinese Art and Archæology in the \\ University of London
}

" $\mathrm{A}$ no period in the history of the world has the attention of civilized nations been so fully directed towards China, its early history and modern position as at the present moment." These words, though true to-day, were in fact written exactly a century ago to preface the catalogue of London's first Chinese Exhibition. It was the enterprise of an American, named Nathan Dunn, who, during twelve years spent in China as a merchant, had collected the 1,341 exhibits, representing, so he claimed, "the Chinese world in miniature". More than fifty thousand persons visited his collection in a pavilion built for it near Hyde Park Corner. Presumably the exhibits were in due course shipped back to their owner in Philadelphia.

The next display of the kind remained in England and so contributed to the beginnings of our Chinese 
collections. At the wish of the Prince of Wales, a special invitation to take part in the International Fisheries Exhibition of 1883 had been sent to the Chinese Government, which responded by instructing the Inspectorate-General of Maritime Customs to make the necessary arrangements. The resultant Chinese Court in the Exhibition at South Kensington was a great success, and it continued with additions to do service at two other International Exhibitions, Health and Inventions, held in 1884 and 1885 respectively.

The catalogue of the Chinese part at the Health Exhibition shows that the intention was, like that of Mr. Dunn, to represent the material civilization of everyday China. There were typical living-rooms fully furnished, lay figures dressed in costumes worn by every class, various means of transport including a catafalque, stoves, weapons and a macabre item in an effigy of a dead Buddhist priest undergoing cremation. Thirty Chinese came from China: ten shopkeepers to ply their trade in four well-stocked shops; ten cooks to supply Chinese dishes in the restaurant; six musicians to sing, play and act; a carpenter, a painter and two barbers to exercise their callings in public. As to the shops, the carved fronts for which came from China, one was occupied by a Peking firm of curio dealers, one by a firm from Kiukiang with modern porcelain, one by tobacconists from Hankow, and one by a Canton firm selling miscellaneous fancy goods.

These exhibitions marked a new phase. Since the sixteenth century, when free intercourse by sea began between the Far East and the West, products of Chinese craftsmanship had been imported in profusion. Few houses of the well-to-do in Britain lacked some example, and the strange charm of these things inclined our forefathers to accept unhesitatingly fanciful and Utopian accounts of their place of origin. Indiscriminate admiration for Chinese notions and products, and those supposedly Chinese, was the vogue. Towards the latter part of the eighteenth century fashion changed and intellectual Europe became obsessed with the world of ancient Greece and Rome. In the nineteenth century commerce and other contacts increased our opportunities of knowing the real China, and then we started to explore the field of art and archrology in earnest. The notable collection of Mr. A. W. Franks (afterwards Sir Wollaston Franks), first exhibited in 1876, passed in time to the British Museum and provided the foundation of Chinese ceramic collections there. The exhibition in 1876 was ably described by $\mathrm{Mr}$. Franks in a remarkable catalogue which shows a true scientific spirit. But the greatest advance in such studies was achieved by the numerous writings of Dr. S. W. Bushell, who had the advantage of contact with Chinese scholars while serving as medical officer to the British Legation in Peking during 18681899. He it was in 1882 who made a basic contribution to the Victoria and Albert Museum by undertaking to buy for it a number of objects of Chinese craftsmanship, chiefly porcelain. For the same Museum he wrote two volumes of a handbook on "Chinese Art", published in 1904 and 1906, which as to scope and scholarship was a pioneer work and has not yet been bettered in some respects. Another medical man did a like service as to Chinese painting. William Anderson, who had been professor of anatomy and surgery at a college in Tokyo, sold his collection of paintings to the British Museum in 1882. Of these, 114 were Chinese, and they formed a nucleus. Four years later was published his catalogue of Chinese and Japanese paintings in the Museum, the first serious study of the subject in a Western language-again an instance of British initiative.

Such were the signs during the middle nineteenth century of reawakened interest in the material culture of China. In both our great national museums progress was quickened by bequests and the example of private collectors. For example, George Salting allowed for more than twenty years his unrivalled collection of some two thousand pieces of Ch'ing porcelain to be displayed in the Victoria and Albert Museum, and bequeathed it to remain there after his death, which occurred in 1910. Our greatest collector was George Eumorfopoulos. During the first thirtyfive years of this century he gathered together with rare enterprise and acumen more than four thousand objects representative of nearly all media of Chinese art and craftsmanship. His collection set a new standard; it was bought for the nation in 1935 and then divided between the British and the Victoria and Albert Museums.

Mention has not yet been made of bronzes, because they scarcely figured at all in the early days. Probably Eumorfopoulos was the first to recognize the significance of ritual bronzes as the chief monuments of ancient Chinese civilization and basic criteria for the beginnings of Chinese art. Even Bushell seems to have been unacquainted with the best archaic bronzes, if one may judge from his writings. Though Eumorfopoulos gradually added many to his collection, no truly representative lot of bronzes had been seen in Great Britain until the great International Exhibition of Chinese Art in London, which during less than four months in 1935-36 attracted nearly half a million visitors. Many considered the bronzes the most illuminating exhibit because of the carefully chosen series of 108 pieces lent by the Chinese Government. Undoubtedly this display, so essential to an understanding of early Chinese culture, created a deep impression and stirred collectors to fresh effort. Quite a number now own notable bronzes: for example, Sir Alan Barlow, Mr. Robert Bruce, Mr. A. E. K. Cull, Sir Herbert Ingram, Sir Neill Malcolm, Mr. H. Oppenh.im and Mr. and Mrs. Walter Sedgwick. The Cull Collection, small yet important, may be studied in a published catalogue.

From the first the ceramics have been better represented than any other medium. An attempt at a statistical survey would be wearisome; suffice it to say that almost all museums in Britain have some specimens, but comprehensiveness is approached in none except the British and the Victoria and Albert. The Lady Lever Art Gallery at Port Sunlight has a

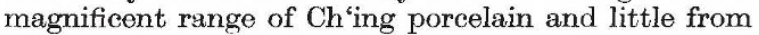
other periods. That reflects the prevailing aim of collectors in the last century, who were content with these superb later products. During recent decades the fashion has been to seek the wares of earlier periods, and some remarkable collections are the outcome. Those of Sir Alan Barlow, Mr. and Mrs. Alfred Clark, Sir Percival David and Sir Herbert Ingram should be mentioned. The Clark Collection may be studied from photographs at the Courtauld Institute of Art, and an account of the David Collection has been published. The Ingram Collection is specially strong in Yüeh ware.

In a short article omissions are inevitable. Yet jade must not be left out, since it has always figured prominently in the social and religious life of China. That ardent connoisseur, the late Oscar Raphael, 
had a special liking for jade. His fine collection of Chinese antiquities in jade and other media was bequeathed to the British and Fitzwilliam Museums. Numerous jade carvings are among Sir Charles Hardinge's collection of 2,539 small objects made of more than a hundred different materials, the whole affording striking evidence as to Chinese beliefs, customs and handicrafts. Also of ethnological value is the Chinese section in the Wellcome Historical Medical Museum. It contains, besides drugs and acupuncture instruments, very diverse exhibits, including many amulets. The student will find special satisfaction in the Cambridge University Museum of Archæology and Ethnology, because here are weapons, tools, currency and pottery from the earliest times, all arranged in chronological sequence. Finally, a word is due concerning the inscribed bone and tortoise-shell fragments found near An-yang at the end of last century. They put back the limits of authentic history and tell us of Chinese civilization more than three thousand years ago. In all, some 2,820 of these fragments belong to three collections : in the Royal Scottish and British Museums and in the ownership of Mr. L. C. Hopkins, doyen of the few Western students of archaic Chinese script.

To sum up: there are public and private collections in Britain rich in objects with æsthetic appeal, but poor in those not classed as 'art' which throw equal light on the history of Chinese civilization. Except in the aforesaid Cambridge Museum, small effort seems to have been made to trace evolutionary sequence in the ordinary things of life. Our collections are much scattered and duplicated; we need a central Chinese Museum.

\section{NEWS and VIEWS}

\section{Visit of Indian Men of Sclence}

Ir is now expected that the distinguished Indian scientific men who will shortly visit Great Britain will arrive about the second week of October. They expect to stay in England for about seven weeks, during which time they will visit important scientific laboratories and industrial, medical and agricultural research institutions in and near London in the Midlands and north of England and elsewhere in the United Kingdom; they will also discuss modern scientific progress with such bodies as the Royal Society, the Department of Scientific and Industrial Research, the Medical Research Council, the Agricultural Research Council and the Radio Board. This visit is a sequel to the visit to India last winter of Prof. A. V. Hill, secretary of the Royal Society. It was then suggested that Indian scientific men should be given an opportunity of coming to the United Kingdom and of establishing closer relations between the many new scientific organizations in India and corresponding organizations here. The proposal was warmly welcomed by H.M. Government and by the Government of India. They will be the guests of His Majesty's Government while they are in Great Britain.

The party will probably consist of the following: Dr. Nazir Ahmad, director of the Cotton Technological Laboratory, Matunga, Bombay; Colonel S. L. Bhatia, deputy director-general of the Indian Medical Service; Sir Shanti S. Bhatnagar, director of scientific and industrial research, India; Sir Jnan Chandra Ghosh, director of the Indian Institute of Science, Bangalore, and president of the National Institute of Sciences of India; Prof. S. K. Mitra, of the University College of Science, Calcutta, chairman of the Radio Committee of the Board of Scientific and Industrial Research; Prof. J. N. Mukherjee, professor of chemistry, University of Calcutta; Prof. Megh Nad Saha, of the University College of Science, Calcutta. Colonel Bhatia's departure from India is expected to be delayed, and he will not join the party until later.

\section{Professorship of Concrete Technology at the Imperial College, London}

A ReCENT benefaction from the Cement Makers' Federation has enabled the Imperial College, with the approval of the University of London, to institute in its City and Guilds College a new chair of concrete technology. It may not be possible to appoint a professor until after the termination of war with Germany. The chair will be instituted in the first instance for ten years, and will be attached to the existing Department of Civil Engineering. The duties of the professor will be to provide advanced instruction in the principles and technological application of reinforced concrete, to conduct research in his subject, and to consult with industry regarding the practical experience which it will give to students in training. In order to establish the necessary contact with industry, an advisory committee is contemplated, with appropriate representation of interested bodies, which will report to the governing body of the College. At the end of the ten-year period it will review the working of the scheme and advise as to its continuation or termination. A noteworthy feature of the scheme, which might well be followed as a model in future planning of training for technology, is an arrangement, sponsored by a number of building and eivil engineering contractors, whereby bursaries will be made available to students devoting one or two years (after a preliminary study of the basic sciences) to intensive study of concrete technology. It has been agreed that industry looks for graduates broadly trained in the fundamental sciences, but with specialized knowledge superimposed; and that its willingness to provide such bursaries is the best assurance that can be given of its intention to absorb men who have thus committed themselves to a specialized course of training.

\section{Prof. Frank Allen}

Prof. Frank Allen has just retired from the position of head of the Department of Physics, of the University of Manitoba, Winnipeg, Canada, after forty years of service. He is a native of Canterbury, New Brunswick, born on February 6, 1874, and is thus one of the great army of educationists given by the Maritime Provinces of Canada to the West. After graduation from the provincial University of New Brunswick in 1900, he spent four years at Cornell, at a time when the United States physicists were just beginning to realize the importance of their calling. Allen received his Ph.D. degree at Cornell and in the autumn of 1904 entered on his work in Manitoba. He has made an important contribution to physics in Canada. $\mathrm{He}$ was elected a fellow of the Royal Society of Canada in 1909 and served as a member of the National 